\title{
Influence of the melting temperature on the measurement of the mass concentration and size distribution of black carbon in snow
}

\author{
Takeshi Kinase $^{1}$, Kazuyuki Kita ${ }^{1}$, Yoshimi Tsukagawa-Ogawa ${ }^{2}$, Kumiko Goto-Azuma ${ }^{2,3}$, and Hiroto Kawashima ${ }^{4}$ \\ ${ }^{1}$ Earth Sciences Course, Graduate School of Science and Engineering, Ibaraki University, Mito, Japan \\ ${ }^{2}$ National Institute of Polar research, Tachikawa, Japan \\ ${ }^{3}$ Department of Polar Research, SOKENDAI, The Graduate University for Advanced Studies, Tachikawa, Japan \\ ${ }^{4}$ Department of Management Science and Engineering, Faculty of System Science \& Technology, Akita Prefectural \\ University, Yuri-Honjyo, Japan
}

Correspondence to: T. Kinase (10nd4021@vc.ibaraki.ac.jp), K. Kita (kazuyuki.kita.iu@vc.ibaraki.ac.jp), Y. Ogawa (ogawa.yoshimi@nipr.ac.jp), K. Goto-Azuma (kumiko@nipr.ac.jp), H. Kawashima (kawashima@akita-pu.ac.jp)

Received: 23 October 2015 - Published in Atmos. Meas. Tech. Discuss.: 18 January 2016

Revised: 4 April 2016 - Accepted: 5 April 2016 - Published: 29 April 2016

\begin{abstract}
The influence of temperature and time of snow sample melting on the measurement of mass concentration and size distribution of black carbon (BC) in snow was evaluated experimentally. In the experiments, fresh (Shirouma) and aged (Hakusan) snow samples were melted at different temperatures or at different time lengths, and the $\mathrm{BC}$ mass concentration and size distribution in the melted snow samples were measured using a nebulizer and a single-particle soot photometer (SP2). In the experiment where melting temperature was varied, the $\mathrm{BC}$ mass concentration in the liquid decreased at a melting temperature of $70^{\circ} \mathrm{C}$. This decrease was $8.0 \%$ for the Shirouma sample and $46.4 \%$ for the Hakusan sample and depended on BC particle size, with a significant decrease found at $\mathrm{BC}$ diameters less than $350 \mathrm{~nm}$. A similar decrease in $\mathrm{BC}$ mass concentration was found when the Hakusan snow sample that had been melted at $5{ }^{\circ} \mathrm{C}$ was heated to $70^{\circ} \mathrm{C}$. The experiment in which melting time was varied indicated that $\mathrm{BC}$ mass concentration in the liquid did not change for the Shirouma sample but decreased significantly with a longer melting time for the Hakusan sample $(38.6 \%)$. These results indicate that melting of snow samples at high temperatures or over long time periods can significantly affect the measurement of BC mass and its size distribution, especially for aged snow samples.
\end{abstract}

\section{Introduction}

Black carbon (BC), commonly referred to as soot, strongly absorbs solar radiation in the atmosphere, leading to significant climate effects. The deposition of $\mathrm{BC}$ onto snowpacks/ice packs also leads to positive radiative forcing because it can significantly reduce snow/ice albedo (Bond et al., 2013; Warren and Wiscombe, 1980; Wiscombe and Warren, 1980). The snow/ice albedo effect of BC, together with other processes (water supply, grains, etc.), also accelerates the melting of snow and ice (Aoki et al., 2011; Brandt et al., 2011). Therefore, numerous studies have been conducted to measure BC concentration in snow/ice and estimate its influence on the climate via radiative forcing, surface albedo, and so on.

In the latest report by the Intergovernmental Panel on Climate Change (IPCC, 2013), the global radiative forcing of $\mathrm{BC}$ in snow since 1875 was estimated to be $0.04 \mathrm{Wm}^{-2}$, with a $90 \%$ uncertainty range between +0.02 and $+0.09 \mathrm{Wm}^{-2}$. Bond et al. (2013) also provided a central estimate of $0.04 \mathrm{Wm}^{-2}$, between +0.01 and $+0.09 \mathrm{Wm}^{-2}$. Such work shows that there remains a large uncertainty in the estimation of the climate effects of $\mathrm{BC}$ on snow/ice; therefore, more studies are necessary on BC in snow, including the improvement of its measurement techniques.

The mass concentration of $\mathrm{BC}$ in snow/ice is commonly measured using one of the following three methods. The first utilizes light absorption by the BC. In this method, a snow sample is melted and filtered. Diffuse light is irradiated to 
the filter to measure its light transmission, and the mass of $\mathrm{BC}$ retained on the filter is derived from the decrement of the transmission (Clarke and Noone, 1985; Grenfell et al., 2011; Warren and Clarke, 1990). The second method utilizes the thermal optical technique. In this method, elemental carbon (EC), rather than $\mathrm{BC}$, is measured. The snow sample is melted and filtered with a quartz fibre filter. The EC retained on the filter is thermally converted to $\mathrm{CO}_{2}$ gas, and the mass of EC is derived by measuring the $\mathrm{CO}_{2}$ concentration (Aoki et al., 2011; Chow et al., 2001, 2007; Jenk et al., 2006; Lavancy et al., 1999). The third method utilizes the single-particle soot photometer (SP2). In this method, snow samples are melted and aerosolized using a nebulizer. The mass and size of each aerosolized BC particle are measured with the SP2 instrument (Lim et al., 2014; McConnell et al., 2007; Ohata et al., 2013; Schwarz et al., 2012, 2013). This method has the advantage that it provides not only the total $\mathrm{BC}$ mass but also the size distribution of $\mathrm{BC}$ particles in the snow. The $\mathrm{BC}$ size distribution is very important because it significantly affects the mass absorption cross section of BC in snow (Schwarz et al., 2013). There are several factors affecting the uncertainty of measured $\mathrm{BC}$ mass concentration by using these methods, and several studies have been performed to reduce such uncertainty and increase precision and reliability. For example, Mori et al. (2016), Ohata et al. (2011, 2013), Schwarz et al. (2012), and Wendl et al. (2014) estimated uncertainties in the SP2 method by evaluating the size-dependent efficiency of certain nebulizers, the effect of agitation of a liquid BC sample, calibration techniques, etc. Although the melting of snow/ice samples is a common procedure in the three methods above, uncertainties due to this procedure have not yet been fully examined. Many researchers use a microwave oven or hot water bath for melting snow/ice samples faster, to reduce BC loss onto the inner walls of sample containers as well as variation in the BC size distribution (e.g., Brandt et al., 2011; Doherty et al., 2010; Schwarz et al., 2012; Warren and Clarke, 1990). However, some studies suggest that the heating condition for melting snow/ice samples may significantly affect the $\mathrm{BC}$ mass concentration and its size distribution in the melted water, leading to possible uncertainty in the measurement of BC mass in snow/ice. Schwarz et al. (2012), Lim et al. (2014), and Wendl et al. (2014) indicated that freezing and melting cycles significantly affect BC mass concentration and size distribution in water, and that it is possible that $\mathrm{BC}$ size distribution can provide information about the thermal history of the snow. Lim et al. (2014) evaluated sample treatment procedures in the SP2 method, including the melting procedure, freezing/melting cycle, and surface area to volume ratio of the sample containers. They compared two snow melting procedures, melting at room temperature and melting in a warm bath $\left(30^{\circ} \mathrm{C}\right)$, but did not find a significant difference in the measured $\mathrm{BC}$ concentration between the two procedures. They suggested that faster melting of snow samples is preferable and that the melting temperature does not significantly affect the measurement. However, considering that higher temperatures have been adopted for the faster melting of snow/ice samples using a microwave oven in several studies, the influence of temperature should be evaluated for a broad temperature range. It is possible that the history of snow/ice samples, such as various chemical species deposited on snow or the cycles of partial melting and refreezing, affects the influence of the melting conditions on the measurement.

In this study, experiments to measure $\mathrm{BC}$ mass and size distribution in fresh and aged snow samples melted at various temperatures and over various lengths of time were conducted with the SP2 instrument (Droplet Measurement Technology, Boulder, Colorado, USA). By comparing the results for the different temperatures and the time lengths, their influence on BC measurement in snow/ice are evaluated.

\section{Experiment}

\subsection{Snow samples}

The snow samples used in this study were obtained from two locations: Hakusan $\left(36^{\circ} 17^{\prime} \mathrm{N}, 136^{\circ} 62^{\prime} \mathrm{E}\right)$ and Shirouma $\left(36^{\circ} 76^{\prime} \mathrm{N}, 137^{\circ} 88^{\prime} \mathrm{E}\right)$, Japan. Sampling was conducted on 13 and 21 March 2013, respectively. The Shirouma sample was fresh, powder snow, sampled within $6 \mathrm{~h}$ of the snowfall. The Hakusan sample consisted of aged, granular snow that was sampled approximately 2 weeks after the snowfall. This sample probably experienced partial melting (by sunlight heating or rainfall) and refreezing; therefore, it was likely more inhomogenized. After the sampling, these samples were stored in polypropylene (PP) containers at temperatures below $-30^{\circ} \mathrm{C}$. In order to make the snow samples more uniform, they were stirred well with a mixer in a low temperature laboratory (room temperature of $-30^{\circ} \mathrm{C}$ ) at the National Institute of Polar Research. After stirring, samples were divided and melted. All containers and bottles used in this study had already been cleaned with ethanol and ultrapure water.

\subsection{Melting process}

In this study, two experiments were performed to evaluate the influence of melting temperature and melting time length. For the experiment to evaluate the former influence (melting temperature experiment), each (Hakusan or Shirouma) snow sample was stirred in a $500 \mathrm{~cm}^{3}$ bottle and then divided into nine $30 \mathrm{~cm}^{3}$ glass bottles for melting. Snow samples in each three of these nine bottles were melted in a water bath at one of three temperatures: 5,20 , and $70^{\circ} \mathrm{C}$. In order to control the melting temperature accurately, we did not use a microwave oven. Inhomogeneity in each snow sample was estimated using the range of measurement results for the three bottled samples melted at the same temperature. In comparison to the melting temperature experiment, the experiment to eval- 
uate the influence of melting time length (melting time experiment) used a larger amount of snow (sampled across a wider area at Shirouma or to a larger depth at Hakusan). Therefore, the $\mathrm{BC}$ mass concentration in each snow sample was not necessarily identical across the two experiments. In the melting time experiment, each snow sample was stirred in a $6000 \mathrm{~cm}^{3}$ metallic can and then divided into three $30 \mathrm{~cm}^{3}$ glass bottles and one $500 \mathrm{~cm}^{3}$ glass bottle. Snow samples in these bottles were melted in a refrigerator at a temperature of approximately $1{ }^{\circ} \mathrm{C}$. Differences in bottle volume affected melting time length: it took $2-3 \mathrm{~h}$ to melt snow samples in the $30 \mathrm{~cm}^{3}$ bottles and more than $6 \mathrm{~h}$ for the $500 \mathrm{~cm}^{3}$ bottles. A low temperature $\left(1^{\circ} \mathrm{C}\right)$ was adopted because the melting temperature experiment had previously shown that a lower melting temperature is preferable for snow BC measurement. Moreover, a lower melting temperature allowed for a broader range of melting time lengths.

In both experiments, each bottle or container was closed during melting and storage, and after the melting, samples were not transferred to other containers, so as to minimize the risk of contamination. All liquid samples were sonicated for $15 \mathrm{~min}$ and shaken just before measurement.

\subsection{Measurement of the $\mathrm{BC}$ mass concentration}

The $\mathrm{BC}$ mass concentration and size distribution in the melted samples were measured with an experiment system nearly identical to that used by Ohata et al. $(2011,2013)$ and Mori et al. (2016). Details of the SP2 instrument used have been described elsewhere (Moteki and Kondo, 2007, 2010; Mori et al., 2016; Stephen et al., 2003). The liquid of a melted snow sample was transferred to a concentric pneumatic nebulizer (Marin-5, Cetac Technologies, Inc., Omaha, Nebraska, USA) with a peristatic pump (REGRO Ana$\log$, ISMATEC SA., Feldeggstrasse, Glattbrugg, Switzerland) and aerosolized using dry, filtered air at a flow rate of $15.23 \mathrm{~cm}^{3} \mathrm{~s}^{-1}$. The sample droplets in the airflow were evaporated during passage through a heater tube at $140^{\circ} \mathrm{C}$, and the water vapor in the airflow was removed during passage through a chiller at $3{ }^{\circ} \mathrm{C}$. The $\mathrm{BC}$ and other nonvolatile particles remaining in the airflow were introduced to the SP2 to measure the mass and size of each $\mathrm{BC}$ particle. Mori et al. (2016) calibrated the entire experimental system using simulated BC material. They also determined that the detection efficiency of 200 to $2000 \mathrm{~nm} \mathrm{BC}$ in the liquid was consistently around $50 \%$.

\section{Results}

\subsection{Influence of melting temperature}

Figure $1 \mathrm{a}$ and $\mathrm{b}$ show the median total mass concentration of BC in the melted Hakusan and Shirouma snow samples, respectively. Error bars show the range between minimum and maximum. The total mass concentrations of BC in the Haku-

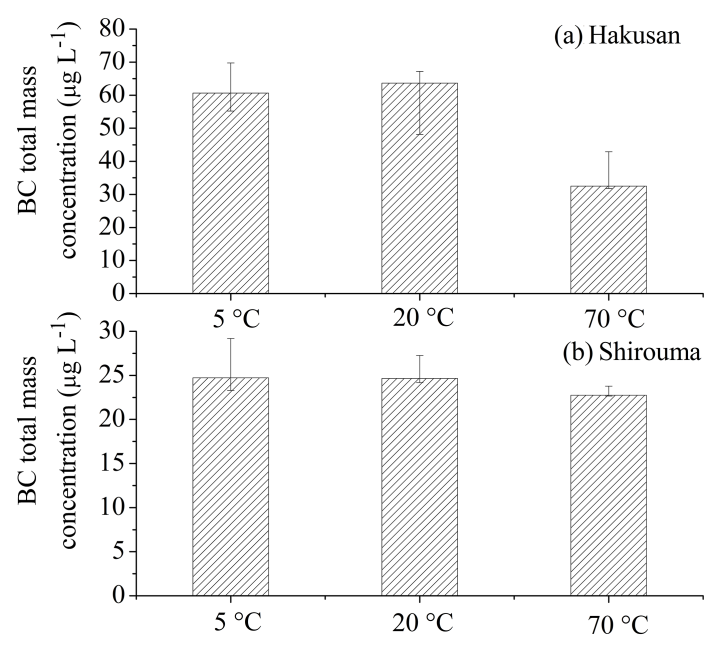

Figure 1. Total mass concentration of BC in (a) Hakusan and (b) Shirouma snow samples melted at 5,20 , and $70^{\circ} \mathrm{C}$.

san snow sample melted at temperatures of 5,20 , and $70{ }^{\circ} \mathrm{C}$ were 60.7 (55.2-69.8), 63.6 (48.1-67.2), and 32.5 (31.842.9) $\mu \mathrm{g} \mathrm{L}^{-1}$, respectively; in the Shirouma snow sample, they were 24.7 (23.3-29.2), 24.6 (24.2-27.3) and 22.8 (22.623.8) $\mu \mathrm{g} \mathrm{L}{ }^{-1}$, respectively. To estimate the drift of the experimental system, repeat measurements of selected samples were conducted after all samples had been measured. The average difference in $\mathrm{BC}$ mass concentration between the first and second measurements was $-2.1 \%(-0.4$ to $-5.1 \%)$. For both samples, the $\mathrm{BC}$ mass concentration values do not show a significant difference between the melting temperatures of 5 and $20^{\circ} \mathrm{C}$; however, the $\mathrm{BC}$ mass concentration was systematically smaller at the $70^{\circ} \mathrm{C}$ melting temperature. In the case of the Hakusan sample, the difference between 70 and $5 / 20^{\circ} \mathrm{C}$ is significant, exceeding random errors from measurement and sample inhomogeneity.

Figure $2 \mathrm{a}$ shows the median mass size distribution of $\mathrm{BC}$ in the Hakusan snow samples melted at temperatures of 5 , 20, and $70^{\circ} \mathrm{C}$; Fig. $2 \mathrm{~b}$ shows the same but for the Shirouma snow sample. For the Hakusan sample, the mass concentration of BC particles with diameters less than $400 \mathrm{~nm}$ is significantly smaller in the snow melted at $70{ }^{\circ} \mathrm{C}$ than that at the other temperatures. For the Shirouma sample, the BC mass size distributions for the three melting temperatures are similar to one other; although, the values at the higher melting temperature are smaller for BC particles of less than $350 \mathrm{~nm}$ diameter. These results show that the $\mathrm{BC}$ mass concentration in melted snow decreases at higher $\left(70^{\circ} \mathrm{C}\right)$ melting temperatures, especially for $\mathrm{BC}$ particles smaller than $350 \mathrm{~nm}$. Figure 3 shows the ratio of the median $\mathrm{BC}$ mass in the samples melted at $70^{\circ} \mathrm{C}$ to those melted at $5{ }^{\circ} \mathrm{C}$, as a function of $\mathrm{BC}$ size. Error bars show the minimum and maximum ratios. This figure shows that the ratio is lower for smaller particle sizes. In addition, considering that the Hakusan sample was aged and had much more BC, the difference between the Shi- 

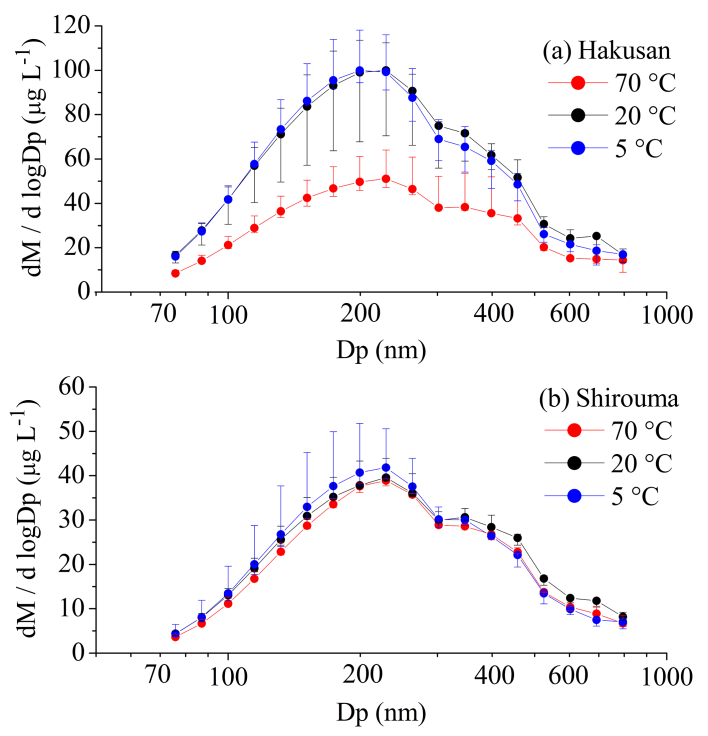

Figure 2. Mass size distribution of BC in (a) Hakusan and (b) Shirouma snow samples melted at 5,20 , and $70^{\circ} \mathrm{C}$, where $\mathrm{M}$ and $\mathrm{Dp}$ denote the mass and diameter of a $\mathrm{BC}$ particle, respectively.

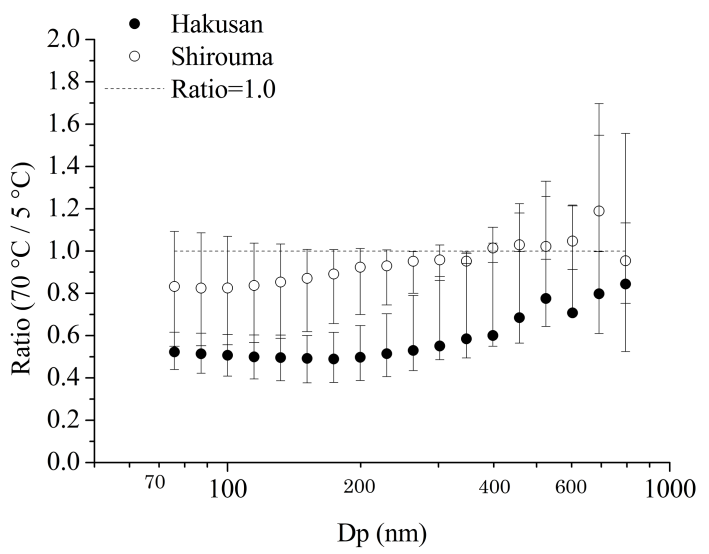

Figure 3. Size distribution of the ratio of the $\mathrm{BC}$ mass concentration in the snow samples melted at $70^{\circ} \mathrm{C}$ to those at $5{ }^{\circ} \mathrm{C}$.

rouma and Hakusan samples suggests that the ratio decrease may depend on the age of the snow (and/or other reasons such as pollution).

The influence of high temperature (or heating) was also evaluated by a further experiment. We heated the liquid of the Shirouma snow sample melted at 5 to $70^{\circ} \mathrm{C}$ and measured the mass size distribution of the BC. Figure 4 shows the size distribution of the $\mathrm{BC}$ mass ratio before and after the heating. The error bars show the reproducibility of the measurement. The ratio decreased significantly with BC diameters below $300 \mathrm{~nm}$ and the decrease was more evident below $150 \mathrm{~nm}$, indicating that reduction of the mass concentration of smaller $\mathrm{BC}$ particles can occur at higher temperature $\left(70^{\circ} \mathrm{C}\right)$ not only during snowmelt but also after melting.

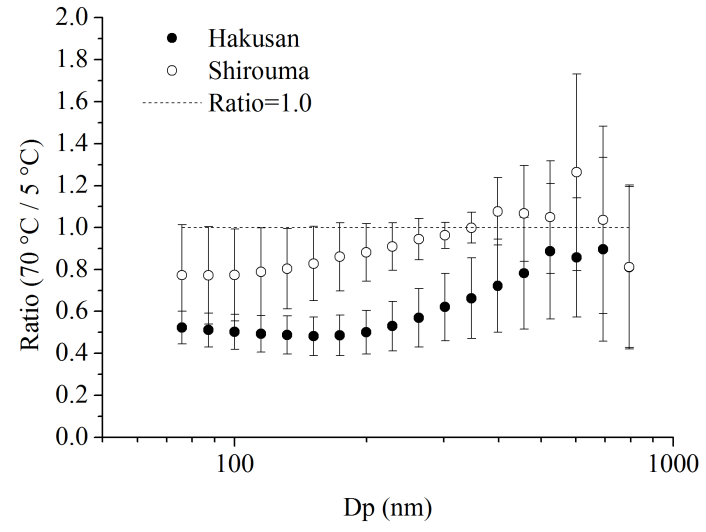

Figure 4. Size distribution of the ratio of the $\mathrm{BC}$ mass concentration in the Shirouma snow sample melted at $5^{\circ} \mathrm{C}$ and heated at $70^{\circ} \mathrm{C}$ to that before heating.

\subsection{Influence of melting time}

Figure $5 \mathrm{a}$ and $\mathrm{b}$ show the median total mass concentration of BC in the melted Hakusan and Shirouma snow samples, respectively, comparing values for the samples melted in the 30 and $500 \mathrm{~cm}^{3}$ bottles. Error bars for the $30 \mathrm{~cm}^{3}$ bottles show the range between the minimum and maximum. Because only one $500 \mathrm{~cm}^{3}$ bottle was measured for each snow sample, the random error range was estimated by assuming that the sample inhomogeneity was the same as that for the three $30 \mathrm{~cm}^{3}$ bottle samples. Concerning repeatability, the Hakusan $500 \mathrm{~cm}^{3}$ bottle sample was measured a second time after other sample measurements, and the difference in $\mathrm{BC}$ mass concentration between the first and second measurements was $7.8 \%$. The time required for melting was approximately $2 \mathrm{~h}$ in the $30 \mathrm{~cm}^{3}$ bottles and exceeded $6 \mathrm{~h}$ in the $500 \mathrm{~cm}^{3}$ bottles. The total mass concentrations of $\mathrm{BC}$ in the Hakusan snow sample melted in the $30 \mathrm{~cm}^{3}$ bottles and $500 \mathrm{~cm}^{3}$ bottles were $37.2(33.9-30.1) \mu \mathrm{g} \mathrm{L}^{-1}$ and $22.9(20.8-24.0) \mu \mathrm{g} \mathrm{L}^{-1}$, respectively. This difference is significant, exceeding the random error range. On the contrary, in the Shirouma snow sample, the values were 16.3 (14.318.2) $\mu \mathrm{g} \mathrm{L}^{-1}$ and $15.1(13.2-16.8) \mu \mathrm{g} \mathrm{L}^{-1}$, respectively. This difference is negligibly small.

Figure 6a shows the median of the mass size distribution of BC in the Hakusan snow samples melted in the $30 \mathrm{~cm}^{3}$ bottles and the $500 \mathrm{~cm}^{3}$ bottle. Figure $6 \mathrm{~b}$ shows the same but for the Shirouma snow samples. Error bars were calculated as above. For both the Hakusan and Shirouma samples, the $\mathrm{BC}$ mass concentration of smaller $\mathrm{BC}$ particles in the $500 \mathrm{~cm}^{3}$ bottle sample was less than those in the $30 \mathrm{~cm}^{3}$ bottle samples. However, the difference in the Shirouma samples was not significant considering the error range. On the other hand, the difference in the Hakusan samples was significantly smaller at diameters less than $850 \mathrm{~nm}$ in the $500 \mathrm{~cm}^{3}$ bottle. Figure 7 shows the size distribution of the median of the $\mathrm{BC}$ 

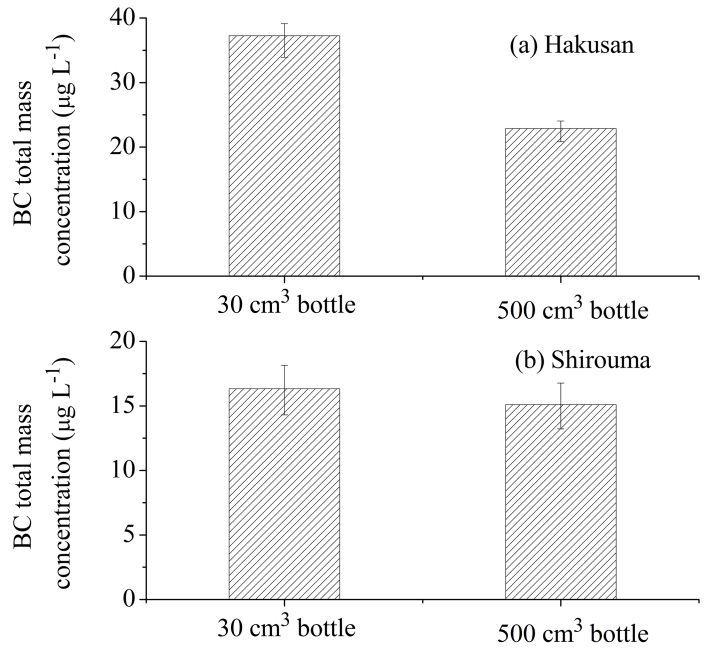

Figure 5. Total mass concentration of $\mathrm{BC}$ in (a) Hakusan and (b) Shirouma snow samples melted in $30 \mathrm{~cm}^{3}$ bottles and a $500 \mathrm{~cm}^{3}$ bottle.
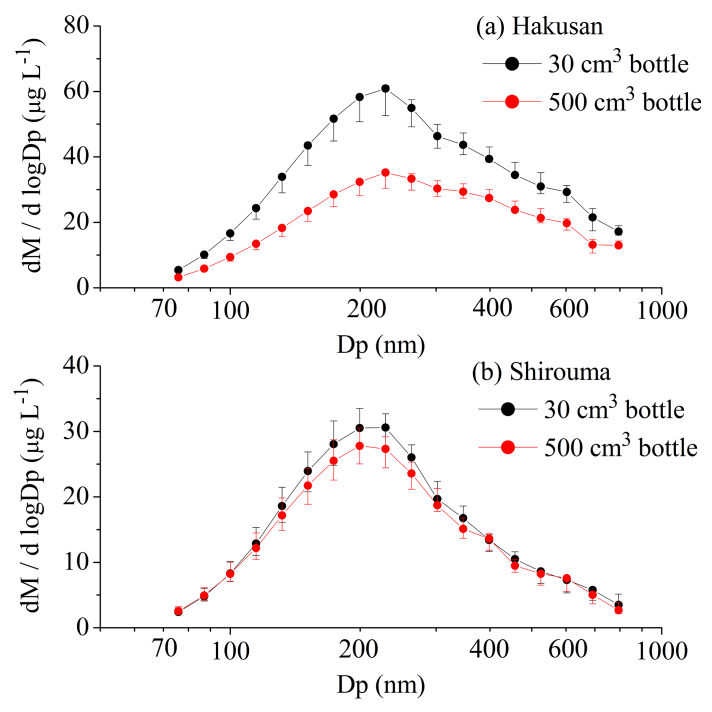

Figure 6. Size distribution of the $\mathrm{BC}$ mass concentration in (a) Hakusan and (b) Shirouma snow samples melted in $30 \mathrm{~cm}^{3}$ bottles and a $500 \mathrm{~cm}^{3}$ bottle.

mass ratio of the $500 \mathrm{~cm}^{3}$ bottle sample to the $30 \mathrm{~cm}^{3}$ bottle samples. Error bars show the minimum and maximum ratios. The ratio is systematically smaller than unity at BC diameters between 100 and $350 \mathrm{~nm}$ for the Shirouma sample; however, this was not significant. The ratio is significantly smaller than unity at BC diameters less than $850 \mathrm{~nm}$ for the Hakusan sample; however, there is no size dependence. These results suggest that reduction of the mass concentration for $\mathrm{BC}$ particles at diameters from 70 to $850 \mathrm{~nm}$ may occur during the melting process, especially for aged and/or more polluted snow. The dependence of this reduction on $\mathrm{BC}$ diameter was not evident unlike that in the melting temperature experiment.

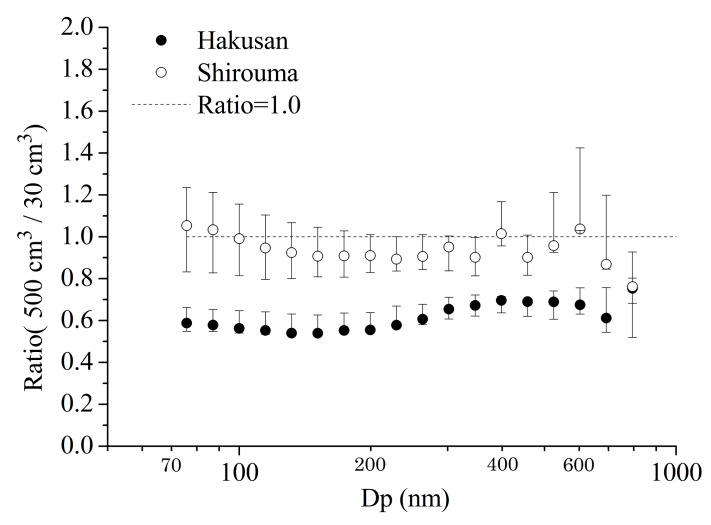

Figure 7. Size distribution of the ratio of the $\mathrm{BC}$ mass concentration in the snow sample melted in the $500 \mathrm{~cm}^{3}$ bottle to that melted in the $30 \mathrm{~cm}^{3}$ bottles.

It is possible that this decrease in BC mass during snowmelt continues after melting is complete. We stored the melted Hakusan and Shirouma samples in the $500 \mathrm{~cm}^{3}$ bottles (capped using teflon packing) in a refrigerator at $1{ }^{\circ} \mathrm{C}$ for 4 days after the melting. The $\mathrm{BC}$ mass was measured repeatedly, at time intervals of about $24 \mathrm{~h}$, to evaluate the influence of storage time. Before each measurement, the sample bottles were sonicated for $15 \mathrm{~min}$ and shaken just before the measurement. No significant difference in total mass and size distribution was found during storage, indicating that significant $\mathrm{BC}$ mass reduction does not occur in the liquid phase during post-melting storage at low temperature. This result is consistent with recent reports. For example, Lim et al. (2014) and Schwartz et al. (2013) showed that the size distribution of $\mathrm{BC}$ mass in melted snow samples is stable over $24 \mathrm{~h}$. Wendl et al. (2014) showed that there is no significant BC loss over 18 days. Ohata et al. (2011) showed that the BC mass concentration in water solution did not significantly change over 50 days. It is suggested that BC mass reduction in our melting experiment occurred during the coexistence of the solid and liquid phases.

\section{Conclusions}

To enable a more accurate measurement of the amount of BC in snow, we evaluated the influence of temperature and time during the procedure for melting snow samples. Using various temperatures (melting temperature experiment) and time lengths (melting time experiment), we melted snow samples and measured $\mathrm{BC}$ mass concentration and size distribution in the melted samples using the SP2 method. Fresh (Shirouma) and aged (Hakusan) snow samples were used in these experiments, and each snow sample was stirred well before the melting process to reduce its inhomogeneity. To reduce the influence of sedimentation and adsorption on the bottle walls, we sonicated and shook all samples immediately prior to the measurements. 
In the melting temperature experiment, snow samples were divided and melted at temperatures of 5,20 , and $70^{\circ} \mathrm{C}$ in a water bath. For both Hakusan and Shirouma snow samples, the measured values of total $\mathrm{BC}$ mass concentration in the liquid melted at $70^{\circ} \mathrm{C}$ were smaller than those in each liquid melted at 20 and $5^{\circ} \mathrm{C}$. The difference between 70 and $5^{\circ} \mathrm{C}$ in the Hakusan sample was larger $(46.4 \%)$ than that in the Shirouma sample $(8.0 \%)$, and this exceeded the random error range. This systematic decrease in the mass concentration at a melting temperature of $70^{\circ} \mathrm{C}$ occurred for $\mathrm{BC}$ particles of less than $350 \mathrm{~nm}$ diameter. A similar decrease in the $\mathrm{BC}$ mass concentration was also found when the snow sample liquid melted at $5{ }^{\circ} \mathrm{C}$ was heated to $70^{\circ} \mathrm{C}$. A similar decrease in the $\mathrm{BC}$ mass was also found in samples stored in liquid form that were heated to $70^{\circ} \mathrm{C}$, indicating that the $\mathrm{BC}$ concentration decrease occurred not only during melting but also during liquid storage. When the liquid was stored at a room temperature or lower, no significant decrease was detected.

The effect of melting time was also tested using the Hakusan and Shirouma snow samples. Subsamples of approximately $30 \mathrm{~cm}^{3}$ took about $2 \mathrm{~h}$ to melt at $1^{\circ} \mathrm{C}$, whereas samples of approximately $500 \mathrm{~cm}^{3}$ took more than $6 \mathrm{~h}$ to melt. In the case of the Shirouma snow sample, measured values of the $\mathrm{BC}$ mass concentration of liquid melted in $30 \mathrm{~cm}^{3}$ and $500 \mathrm{~cm}^{3}$ bottles were nearly the same. In contrast, for the Hakusan snow sample, this value was significantly smaller in liquid melted in the $500 \mathrm{~cm}^{3}$ bottle (about $38.6 \%$ ) than that in the $30 \mathrm{~cm}^{3}$ bottles. The reduction rate in the $500 \mathrm{~cm}^{3}$ bottle was nearly constant at $\mathrm{BC}$ particle diameters of less than $850 \mathrm{~nm}$. Significant BC mass reduction was not found in the liquid phase during storage at low temperature after melting, suggesting that the decrease occurred during the coexistence of the solid and liquid phases.

These experimental results in this study show that to reduce uncertainty in the measurement of BC mass in snow, samples should be melted at low temperature over a short time. The melting temperature experiment showed that it is possible that heating to a high temperature causes a significant reduction in $\mathrm{BC}$ both during the melting process and in the liquid phase. The melting time experiment showed that a slow reduction of $\mathrm{BC}$ concentration can occur even at low temperature during the coexistence of the solid and liquid phases. This suggests that it is inappropriate to melt a large volume snow sample all at once, as done in the lightabsorption and thermal-optical methods, because it would need much time for melting the whole sample. These results also suggest that the temperature history of the snowpack may influence BC mass and size distribution. We identified these influences using only two snow samples, suggesting that greater influences may occur in other snow samples. More systematic studies are necessary to quantify these influences as a function of temperature and snow condition to make the temperature and time conditions preferable for melting snow samples clear.
In this study, the mechanisms of $\mathrm{BC}$ decrease during snowmelt were not examined. The BC mass decrease may have been caused by the adsorption of $\mathrm{BC}$ onto the inner walls of the bottles in which the snow samples were melting. It is also possible that the agglomeration of smaller BC particles into supermicron $\mathrm{BC}$, which was not measured here, caused the apparent decrease in BC mass (especially considering that the decrease of $\mathrm{BC}$ mass was more significant at smaller $\mathrm{BC}$ diameters in the melting temperature experiment). It should be noted that the size dependence of the BC decrease was different in the melting time and melting temperature experiments, suggesting that multiple mechanisms contribute to the BC decrease during snowmelt. Because BC reduction at $1{ }^{\circ} \mathrm{C}$ was found only during snowmelt, this may suggest that it occurs at the interface between the solid and liquid phases. It also should be noted that a significant decrease in BC in the melted snow occurred in the Hakusan snow samples, both in the melting temperature and melting time experiments. This indicates that the influence of melting temperature and melting time length on $\mathrm{BC}$ mass would be more significant in aged snow. The $\mathrm{BC}$ mass concentration in the Hakusan sample was much higher than that in the Shirouma sample. If the BC loss amount was the same in both samples, the influence would be larger in the Shirouma sample; however, the experimental results showed the opposite. We suspect that contaminating chemical substances may have played a role in this BC decrease. Schwarz et al. (2012) showed that the mixing of nitric acid into liquid samples causes a reduction in the mass fraction of supermicron BC particles. Further, Ohata et al. (2011) showed that the influence of $\left(\mathrm{NH}_{4}\right)_{2} \mathrm{SO}_{4}$ and Suwannee River fulvic acid (SRFA) was found when concentration of $\left(\mathrm{NH}_{4}\right)_{2} \mathrm{SO}_{4}$ or SRFA was considerably higher than their typical values in Tokyo. We measured the ion concentrations using ion chromatography (IC-2010, Tosoh Co., Ltd., Tokyo, Japan) in both snow samples. Concentrations of $\mathrm{SO}_{4}^{2-}, \mathrm{NO}_{3}^{-}, \mathrm{Na}^{+}$, and $\mathrm{Cl}^{-}$were significantly higher in the Hakusan sample than those in the Shirouma sample. The concentrations were, respectively, 0.85 , $0.59,0.74$, and $0.80 \mathrm{ppm}$ in the Hakusan sample and 0.15 , $0.12,0.47$, and $0.29 \mathrm{ppm}$ in the Shirouma sample. The level of such pollutants in snow may have contributed to the BC decrease with temperature. Other impurities, for example, dust in the snow, might also play a role via adsorption onto the dust surface. However, the influence of impurities is not yet fully understood; the influence of organic/inorganic substances as well as dust in the snow should be studied in more detail.

Acknowledgements. This work is supported by the National Institute of Polar Research (NIPR) and Ibaraki University. The authors thank S. Ohata, N. Moteki, H. Motoyama, M. Shiobara, Y. Zaizen, and K. Adachi for the experimental support, and Y. Kondo, M. Hayashi, K. Hara, T. Aoki, and K. Kuchiki for the discussions.

Edited by: A. Kokhanovsky 


\section{References}

Aoki, T., Kuchiki, K., Niwano, M., Kodama, Y., Hosaka, M., and Tanaka, T.: Physically based snow albedo model for calculating broadband albedos and the solar heating profile in snowpack for general circulation models, J. Geophys. Res., 116, D11114, doi:10.1029/2010JD015507, 2011.

Bond, T. C., Doherty, S. J., Fahey, D. W., Forster, P. M., Berntsen, T., DeAngelo, B. J., Flanner, M. G., Ghan, S., Kärcher, B., Koch, D., Kinne, S., Kondo, Y., Quinn, P. K., Sarofim, M. C., Schultz, M. G., Schulz, M., Venkataraman, C., Zhang, H., Zhang, S., Bellouin, N., Guttikunda, S. K., Hopke, P. K., Jacobson, M. Z., Kaiser, J. W., Klimont, Z., Lohmann, U., Schwarz, J. P., Shindell, D., Storelvmo, T., Warren, S. G., and Zender, C. S.: Bounding the role of black carbon in the climate system: A scientific assessment, J. Geophys. Res. Atmos., 118, 5380-5552, doi:10.1002/jgrd.50171, 2013.

Brandt, R. E., Warren, S. G., and Clarke, A. D.: A controlled snowmaking experiment testing the relation between black carbon content and reduction of snow albedo, J. Geophys. Res., 116, D08109, doi:10.1029/2010JD015330, 2011.

Chow, J. C., Watson, J. G., Crow, D., Lowenthal, D. H., and Merrifield, T.: Comparison of IMPROVE and NIOSH carbon measurements, Aerosol Sci. Tech., 34, 23-34, doi:10.1080/02786820119073, 2001.

Chow, J. C., Watson, J. G., Chen, L.-W. A., Chang, M. C. O., Robinson, N. F., Trimble, D., and Kohl, S.: The IMPROVE_A Temperature Protocol for Thermal/Optical Carbon Analysis: Maintaining Consistency with a Long-term Database, J. Air Waste Manage, 57, 1014-1023, doi:10.3155/1047-3289.57.9.1014, 2007

Clarke, A. D. and Noone, K. J.: Soot in the Arctic snowpack: a cause for perturbations in radiative transfer, Atmos. Environ., 19, 2045-2053, doi:10.1016/0004-6981(85)90113-1, 1985.

Doherty, S. J., Warren, S. G., Grenfell, T. C., Clarke, A. D., and Brandt, R. E.: Light-absorbing impurities in Arctic snow, Atmos. Chem. Phys., 10, 11647-11680, doi:10.5194/acp-1011647-2010, 2010.

Grenfell, T. C., Doherty, S. J., Clarke, A. D., and Warren, S. G.: Light absorption from particulate impurities in snow and ice determined by spectrophotometric analysis of filters, Appl. Optics, 50, 14, 2037-2048, 2011.

IPCC: Contribution of Working Group I to the IPCC Fifth Assessment Report Climate Change 2013: The Physical Science Basis, 2013.

Jenk, T. M., Szidat, S., Schwikowski, M., Gäggeler, H. W., Brütsch, S., Wacker, L., Synal, H.-A., and Saurer, M.: Radiocarbon analysis in an Alpine ice core: record of anthropogenic and biogenic contributions to carbonaceous aerosols in the past (1650-1940), Atmos. Chem. Phys., 6, 5381-5390, doi:10.5194/acp-6-53812006, 2006.

Lavanchy, V. M. H., Gäggeler, H. W., Schotterer, U., Schwikowski, M., and Baltensperger, U.: Historical record of carbonaceous particle concentrations from a European high-alpine glacier (Colle Gnifetti, Switzerland), J. Geophys. Res., 104, 21227-21236, doi:10.1029/1999JD900408, 1999.
Lim, S., Faïn, X., Zanatta, M., Cozic, J., Jaffrezo, J.-L., Ginot, P., and Laj, P.: Refractory black carbon mass concentrations in snow and ice: method evaluation and inter-comparison with elemental carbon measurement, Atmos. Meas. Tech., 7, 3307-3324, doi:10.5194/amt-7-3307-2014, 2014.

McConnell, J. R., Edwards, R., Kok, G. L., Flanner, M. G., Zender, C. S., Saltzman, E. S., Banta, J. R., Pasteris, D. R., Carter, M. M., and Kahl, J. D. W.: 20th-century industrial black carbon emissions altered arctic climate forcing, Science, 317, 1381-1384, doi:10.1126/science.1144856, 2007.

Mori, T., Moteki, N., Ohata, S., Koike, M., Goto-Azuma, K., Miyazaki, Y., and Kondo, Y.: Improved technique for measuring the size distribution of black carbon particles in liquid water, Aerosol Sci. Tech., 50, 242-254, doi:10.1080/02786826.2016.1147644, 2016.

Moteki, N. and Kondo, Y.: Effects of Mixing State on Black Carbon Measurements by Laser-Induced Incandescence, Aerosol Sci. Tech., 41, 398-417, doi:10.1080/02786820701199728, 2007.

Moteki, N. and Kondo, Y.: Dependence of Laser-Induced Incandescence on Physical Properties of Black Carbon Aerosols: Measurements and Theoretical Interpretation, Aerosol Sci. Technol., 44, 663-675, doi:10.1080/02786826.2010.484450, 2010.

Ohata, S., Moteki, N., and Kondo, Y.: Evaluation of a Method for Measurement of the Concentration and Size Distribution of Black Carbon Particles Suspended in Rainwater, Aerosol Sci. Technol., 45, 1326-1336, doi:10.1080/02786826.2011.593590, 2011.

Ohata, S., Moteki, N., Schwarz, J., Fahey, D., and Kondo, Y.: Evaluation of a Method to Measure Black Carbon Particles Suspended in Rainwater and Snow Samples, Aerosol Sci. Technol., 47, 1073-1082, doi:10.1080/02786826.2013.824067, 2013.

Schwarz, J. P., Doherty, S. J., Li, F., Ruggiero, S. T., Tanner, C. E., Perring, A. E., Gao, R. S., and Fahey, D. W.: Assessing Single Particle Soot Photometer and Integrating Sphere/Integrating Sandwich Spectrophotometer measurement techniques for quantifying black carbon concentration in snow, Atmos. Meas. Tech., 5, 2581-2592, doi:10.5194/amt-5-2581-2012, 2012.

Schwarz, J. P., Gao, R. S., Perring, A. E., Spackman, J. R., and Fahey, D. W.: Black carbon aerosol size in snow, Nat. Sci. Reports, 3, 1356, doi:10.1038/srep01356, 2013.

Stephens, M., Turner, N., and Sandberg, J.: Particle identification by laser-induced incandescence in a solid-state laser cavity, Appl. Opt., 42, 3726-3736, 2003.

Warren, S. G. and Wiscombe, W. J.: A Model for the Spectral Albedo of Snow. II: Snow Containing Atmospheric Aerosols, J. Atmos. Sci., 37, 2734-2745, 1980.

Warren, S. G. and Clarke, A. D.: Soot in the Atmosphere and Snow Surface of Antarctica, J. Geophys. Res., 95, 1811-1816, 1990.

Wendl, I. A., Menking, J. A., Färber, R., Gysel, M., Kaspari, S. D., Laborde, M. J. G., and Schwikowski, M.: Optimized method for black carbon analysis in ice and snow using the Single Particle Soot Photometer, Atmos. Meas. Tech., 7, 2667-2681, doi:10.5194/amt-7-2667-2014, 2014.

Wiscombe, W. J. and Warren, S. G.: A Model for the Spectral Albedo of Snow. I: Pure Snow, J. Atmos. Sci., 37, 2712-2733, 1980. 